\title{
PERSIVALGYMO SUTRIKIMAS: SAMPRATA, PALYGINIMAS SU KITAIS VALGYMO SUTRIKIMAIS IR GYDYMO PAGRINDAI
}

\author{
Milda Musneckytė, Paulina Abraitytė, Tomas Staniulis \\ Lietuvos sveikatos mokslu universiteto Medicinos akademijos Medicinos fakultetas
}

Raktažodžiai: valgymo sutrikimai, anoreksija, bulimija, persivalgymas, nutukimas.

\begin{abstract}
Santrauka
Persivalgymo sutrikimas yra neseniai įtrauktas ị valgymo sutrikimų sąrašą kaip atskiras sutrikimas. Nuo 1959 m. iki 2013 m. persivalgymo sutrikimas buvo laikomas kitų valgymo sutrikimų požymiu. $2013 \mathrm{~m}$. persivalgymo sutrikimas DSM-5 klasifikacijoje atskirtas kaip nauja savarankiška diagnozè. 2015 m. Amerikos maisto ir vaistų tarnyba patvirtino centrinès nervų sistemos stimuliantą lisdeksamfetamino dimesilatą pavadinimu ,Vyvanse“ persivalgymo sutrikimui gydyti. Jis anksčiau buvo naudotas demesio koncentracijos sutrikimo ir hiperaktyvumo sutrikimo gydymui. Persivalgymo sutrikimu sergantiems žmonèms būdingas ydingas santykis su maistu, iškreiptas kūno ịvaizdžio modelio suvokimas bei psichikos problemos, kurios sunkina normalų kasdieni funkcionavimą, socialini gyvenimą ir blogina žmogaus psichoemocinę būseną. Persivalgymo sutrikimas skiriasi nuo kitų valgymo sutrikimų tuo, kad juo sergantys pacientai negali kontroliuoti potraukio persivalgyti, valgymas tampa priemone emocinei įtampai slopinti, tačiau nèra poreikio būti liekniems ir kompensuoti kalorijų perteklių. Tai yra dažna morbidinio nutukimo priežastis. Didelis antsvoris yra svarbus požymis, skiriantis persivalgymo sutrikimą nuo kitų valgymo sutrikimų. Taip pat dèl sunkaus nutukimo laipsnio šie pacientai kenčia antsvorio sukeltas sveikatos problemas ir dažnai nutukimui gydyti kreipiasi į bariatrinès chirurgijos specialistus. Deja, taikant vien tik farmakoterapinį ar chirurgini gydymą, psichologinè persivalgymo problema lieka neišspręsta. Persivalgymo sutrikimas yra kompleksinis sutrikimas, svarbi ir visus veiksnius (psichoemocinę būseną, elgesio modelius bei nutukimą) koreguojanti gydymo taktika, įtraukiant psichoterapiją šalia farmakoterapinio ir chirurginio gydymo.
\end{abstract}

İvadas

Kompulsinis persivalgymas arba persivalgymo sutrikimas literatūroje pirmą kartą paminètas $1959 \mathrm{~m}$. psichiatro A. Stunkard [1]. $1987 \mathrm{~m}$. Amerikos psichiatru asociacija Psichikos sutrikimų diagnostikos ir statistikos vadove (angl. Diagnostic and statistical manual of mental disorders, toliau - DSM) persivalgymo sutrikimą priskyrè vienam iš bulimijos požymių. $1994 \mathrm{~m}$. persivalgymo sutrikimas vis dar nebuvo laikomas savarankiška diagnoze, o priešingai - charakterizuojamas tik kaip vienas iš valgymo sutrikimams būdingų simptomų. Persivalgymo sutrikimas pradètas atidžiau tyrinèti 2008 m., ịkūrus JAV nacionalinę Valgymo sutrikimų asociaciją (angl. Binge eating disorder asociation, sutr. BEDA), padejusią efektyviau diagnozuoti ir diferencijuoti ši sutrikimą nuo kitos valgymo patologijos. $2013 \mathrm{~m}$. persivalgymo sutrikimas buvo ịtrauktas kaip atskira diagnoze į DSM 5 klasifikaciją šalia anoreksijos ir bulimijos. Ankstesnejje klasifikacijoje persivalgymo sutrikimas buvo traktuojamas ne kaip diagnozè, o kitos patologijos požymis, todèl specifinis gydymas iki tol nebuvo plačiai nagrinètas. Nuo 2013 m. gydymo gairèms skirta daugiau dèmesio. $2015 \mathrm{~m}$. JAV maisto ir vaistų kontrolès tarnyba persivalgymo sutrikimui gydyti patvirtino lisdeksamfetamino dimesilatą (Vyvanse), nes buvo pastebètas teigiamas preparato poveikis, reguliuojant persivalgymo simptomatiką. Lisdeksamfetamino dimesilatas - tai centrinę nervų sistemą stimuliuojančių vaistų grupei priskiriamas medikamentas. Iki tol Vyvanse buvo skiriamas gydyti dèmesio koncentracijos ir hiperaktyvumo sutrikimus. Vaisto efektyvumas gydant kompulsinį persivalgymą buvo aprašytas Amerikos medikų asociacijos žurnale. Tyrejjai nustate, kad preparatas reikšmingai sumažina persivalgymo priepuolių skaičių [2]. Persivalgymo sutrikimas vis dar yra nauja diagnozè valgymo sutrikimų klasifikacijoje, todèl teisinga diagnostika bei diferenciacija nuo kitų patologijų, tokių kaip anoreksija ir bulimija, yra labai svarbi, siekiant užtikrinti efektyvų paciento gydymą.

Tyrimo tikslas - apibrèžti persivalgymo sutrikimo sąvoką pagal naujausias DSM-5 rekomendacijas; palyginti 
persivalgymo sutrikimą su kitais valgymo sutrikimais; aptarti pagrindinius persivalgymo sutrikimo simptomus, skiriančius ši sutrikimą nuo kitų valgymo sutrikimų, bei visiems valgymo sutikimams būdingus bendrus požymius, taip pat palyginti skirtingas persivalgymo sutrikimo gydymo metodikas ir jų efektyvumą.

\section{Tyrimo medžiaga ir metodai}

Literatūros apžvalga atlikta lyginant užsienio šaltinių duomenis iš internetinių bibliografinių medicinos duomenų bazių PubMed (Medline), Cohrane, UpToDate. Paieška atlikta naudojant nurodytus raktažodžius ir jų kombinacijas „,binge eating“, „eating disorders“, „,bariatric surgery“. Straipsnių atrankos kriterijai - laisvai prieinami, ne ankstesni nei spausdinti 2009 metais.

\section{Tyrimo rezultatai}

Persivalgymo sutrikimo sąvoka bei samprata. Kompulsinis persivalgymas - tai valgymo sutrikimas, kuriam būdingi nekontroliuojami, periodiški persivalgymo epizodai, lydimi emocinio bei stresinio fono, kai per labai trumpą laiką suvalgomo maisto kiekis dešimtis kartu viršija maisto kiekį, kurį normaliomis sąlygomis žmogus pajègus suvartoti. Priepuoliai kartojasi bent 1 kartą per savaitę, priepuolių trukmè - ne trumpiau nei 6 ménesiai (arba pasikartoja 2 kartus per savaitę ir trunka bent 3 mènesius). Priepuolio metu pacientus lydi bejègiškumo ir kontrolès praradimo jausmas, dèl kurio jie negali nustoti valgę, nors jaučia fizini sotumą. Priepuoliui praejjus, jaučiama gėda ir pasibjauręjimas savimi. Žmonès, sergantys persivalgymo sutrikimu, dažnai valgo vienumoje, vengia su maistu susijusių aplinkybių ir jaučia stiprią psichologinę frustraciją, susijusią su valgymo elgsena kitų asmenų atžvilgiu [3]. Šiuo sutrikimu sergantys pacientai nutunka, jų KMI siekia $35 \mathrm{~kg} / \mathrm{m}^{2}$ ir daugiau, nes sergantiems tikruoju persivalgymo sutrikimu, nebūdingas kalorijų pertekliaus atsikratymas ar kalorijų ribojimas.

Valgymo sutrikimų panašumai bei skirtumai. Persivalgymo sutrikimas turi daug bendrų bruožų su kitais valgymo sutrikimais, tokiais kaip sutrikęs santykis su maistu [4], pakitęs kūno ịvaizdžio suvokimas, bjaurējimasis savo išvaizda, mitybinè elgsena, kuriai būdingas rituališkumas, socialinis nerimas, susijęs su valgymu viešumoje. Šie pacientai, kaip ir sergantys anoreksija bei bulimija, skundžiasi ịvairaus spektro psichikos ir elgesio sutrikimais: depresija, nerimu, miego bei dèmesio koncentracijos sutrikimais, priklausomybėmis, impulsų kontrolès sutrikimais, obsesijomis - kompulsijomis $[5,6]$. Pastebèta, kad asmenybinių sutrikimų turintys žmonès yra labiau linkę sirgti ir valgymo sutrikimais $[7,8]$.

Kompulsinis persivalgymas kategorizuojamas kaip atskiras sutrikimas dẻl kelių požymių, kurie ne visada būdingi sergant anoreksija ar bulimija. Persivalgymo sutrikimu sergantys pacientai dèl nuolat suvartojamo kalorijų pertekliaus [9] ir negebejjimo kontroliuoti poreikio persivalgyti būna labai nutukę, KMI viršija $35 \mathrm{~kg} / \mathrm{m}^{2}$, o tai nebūdinga sergantiems anoreksija ar bulimija [10]. Pacientai dèl didelio nutukimo turi stipriai išreikštų metabolinio sindromo požymių bei kitų sveikatos sutrikimų, todèl dažnai kreipiasi i bariatrinès chirurgijos specialistus [11], o sergantieji bulimija ar anoreksija paprastai būna itin liesi ar normalaus kūno svorio, morbidinis nutukimas jiems nebūdingas. Taip yra dèl to, kad sergančiujų bulimija ir anoreksija kūno įvaizdžio suvokimas sutelktas ị labai liekną konstituciją, bjaurimasi normaliu kūno sudejjimu.

Persivalgymo sutrikimu sergantys pacientai bjaurisi savo nutukusiu kūnu, nepajègia valdyti impulsyviai kylančio poreikio valgyti. Maistas ir valgymas jiems yra priemonè slopinti emocijas ir sumažinti įtampą, nors persivalgymas taip pat kelia stresą ir dar didesnį norą persivalgyti. Valgyti nustojama tik tada, kai daugiau nebeįmanoma fiziškai [12]. Kartais pasitaiko maisto ribojimo epizodų bei dietų, tačiau viskas baigiasi nauju persivalgymo priepuoliu. Kalorijų pertekliaus kompensavimas vis dar yra diskutuotinas, todèl teigti, kad jis būdingas sergantiems persivalgymo sutrikimu, negalima. Jei ir atsikratoma suvalgyto maisto, tai daroma ne dẻl poreikio lieknai atrodyti ar jaučiamos apsivalgymo kaltès.

Dalis persivalgymo sutrikimu sergančių pacientų pažymi, jog yra bandę vartoti laisvinamuosius, diuretikus ar išvemti suvalgytą maistą, tačiau tai aiškina nuolatinio maisto pertekliaus sukeltais virškinimo sutrikimais, o sergantieji bulimija ar anoreksija vartoja laisvinamuosius bei diuretikus, bando išsivemti net suvalgę nedidelị kiekị maisto dèl jaučiamo kaltès jausmo ar noro lieknai atrodyti [13].

Alinantis sportas ir besaikès treniruotés labiau paplitusios tarp sergančiųjų anoreksija ir bulimija, o sergančiuju persivalgymo sutrikimu fizinès veiklos galimybès ne tik labai ribotos dèl didelio nutukimo, bet ir pacientai nerodo poreikio lieknèti sportuojant.

Persivalgymo sutrikimas, anoreksija ir bulimija skiriasi tarpusavyje ir teisinga diferenciacija yra labai svarbi, siekiant parinkti teisingą gydymo taktiką.

Persivalgymo sutrikimo gydymas. Vienas iš pagrindinių persivalgymo sutrikimo požymių yra morbidinis nutukimas, todèl pacientai dažnai nebegali numesti svorio tik mitybos korekcijos ar fizinès veiklos pagalba [14]. Dèl šios priežasties jie dažnai kreipiasi ị skrandžio stemplès ir endokrininès chirurgijos specialistus, kur svorio mažinimui taikomos skrandžio tūrį mažiančios operacijos [15]. Gydant nutukimą chirurginiu būdu, pašalinamos tik persivalgymo sutrikimo pasekmès, sukeliančios su nutukimu susijusius endokrininès sistemos sutrikimus, medžiagų apykaitos sutrikimus, širdies 
ir kraujagyslių ligas. Efektyviausias valgymo sutrikimų gydymo metodas yra kombinuotas gydymas. Persivalgymo sutrikimas - tai daugiaveiksnè būklè, kurią gydant svarbu pašalinti visus fizinès ir psichinès sveikatos sutrikimų mechanizmus. Mitybos koregavimas, fizinè veikla ar chirurginis nutukimo gydymas svarbus siekiant pagerinti paciento fizinę būklę ir organizmo funkcionavimą, užkirsti kelią II tipo cukrinio diabeto, arterinès hipertenzijos, širdies ligų vystymuisi, didelio nutukimo sukeltiems sąnarių, stuburo pakitimams [16]. Skiriant medikamentini gydymą psichikos sutrikimų sukeltų reiškinių mažinimui bei taikant gydymą psichoterapija, grąžinamas sveikas santykis su maistu ir formuojamas normalus kūno įvaizdžio suvokimas [17]. Taip sumažinama psichologine frustracija ir negatyvus emocinis fonas, formuojami nauji elgesio modeliai, todèl persivalgymo priepuoliai kartojasi rečiau [18]. Pastebèta, kad sergantiems persivalgymo sutrikimu ir bariatrinès chirurgijos metodais gydytiems pacientams papildomos psichoterapeuto konsultacijos padeda pasiekti geresnių rezultatų: numetama daugiau svorio, pacientai rečiau patiria atkryčius ar pooperacines komplikacijas dèl dietos apribojimų nesilaikymo, gerẻja jų psichologinè būsena, pagerėja impulsų kontrolè [19]. Ne mažiau svarbus ir tinkamas medikamentinis gydymas, skiriamas nerimo, depresijos, miego bei nuotaikos sutrikimų simptomų slopinimui, taip pagerinant kasdieni paciento funkcionavimą, darbingumą, nuotaiką ir bendrą psichinę sveikatą [20]. Norint pagerinti pacientų svorio korekciją, psichologinę būseną, santykị su savimi bei maistu, tikslinga taikyti ne vienos rūšies gydymą, bet derinti įvairius gydymo metodus: farmakoterapiją bei psichoterapiją, chirurgiją - siekiant koreguoti impulsų kontrolę, mitybinę elgseną, antsvorị [19]. Tinkamas atsakas ị gydymą yra pagerèjusi pacientų organizmo būklè, bendra gyvenimo kokybè, santykis su maistu bei socialiniai aspektai [21-23].

\section{Išvados}

1. Kompulsinis persivalgymas - tai atskira valgymo sutrikimų rūšis, kuriai būdingas morbidinis nutukimas (paciento KMI siekia $35 \mathrm{~kg} / \mathrm{m}^{2}$ ir daugiau) dèl nuolat suvartojamo per didelio kalorijų kiekio, dažnai pasikartojantys persivalgymo epizodai, lydimi emocinio fono, bejëgiškumo jausmo, negalejjimo pasipriešinti potraukiui persivalgyti. Sutrikimas sukelia ne tik somatines su nutukimu susijusias sveikatos problemas, bet daro didelę ittaką žmogaus psichinei sveikatai ir psichologinei būsenai.

2. Naujoje valgymo sutrikimų klasifikacijoje persivalgymo sutrikimas atskirtas nuo bulimijos ir anoreksijos, sudarant daugiau gydymo galimybių sergantiesiems persivalgymo sutrikimu.

3. Taikant psichoterapiją, atkuriamas normalus santykis su maistu ir koreguojamas iškreiptas kūno ịvaizdžio modelis. Medikamentinis gydymas padeda kontroliuoti impulsyvų norą valgyti, gerejja bendroji paciento psichikos būklè, o taikant bariatrinès chirurgijos metodus, efektyviau mažinamas kūno svoris [18]. Paciento požiūris ị save tampa mažiau negatyvus, padidejja darbingumas, gerejja nuotaika ir kinta ydingi mąstymo modeliai, skatinantys persivalgymą ir priklausomybę nuo maisto, žmogus grịžta ị normalų gyvenimą, pagerèja fizinè sveikata ir užtikrinamas visapusis psichoemocinis komfortas.

\section{Literatūra}

1. Stunkard AJ. Eating patterns and obesity. Psychiatr Q 1959;33(2):284-95. https://doi.org/10.1007/BF01575455

2. Reas DL, Grilo CM. Pharmacological treatment of binge eating disorder: update review and synthesis. Expert Opin Pharmacother 2015;16(10):1463-78.

https://doi.org/10.1517/14656566.2015.1053465

3. Byrne R, Kirschner K. Unusual behaviours. Nelson pediatric symptom-based diagnosis. Elsevier 2018, 421-438. https://doi.org/10.1016/B978-0-323-39956-2.00027-3

4. Rosen JC. Improving body image in obesity. In Thompson JK (ed.). Body image, eating disorders, and obesity: an integrative guide for assessment and treatment. American Psychological Association 2020;425-40.

https://doi.org/10.1037/10502-017

5. Peterson CB, Miller KB, Crow SJ, Thuras P, Mitchell JE. Subtypes of binge eating disorder based on psychiatric history. Int $\mathrm{J}$ Eat Disord 2005;38(3):273-6. https://doi.org/10.1002/eat.20174

6. Yanovski SZ, Nelson JE, Dubbert BK, Spitzer RL. Association of binge eating disorder and psychiatric comorbidity in obese subjects. Am J Psychiatry 1993;150(10):1472-9.

https://doi.org/10.1176/ajp.150.10.1472

7. Sylvers P, Lilienfeld SO, LaPrairie JL. Differences between trait fear and trait anxiety: implications for psychopathology. Clin Psychol Rev 2011;31(1):122-37.

https://doi.org/10.1016/j.cpr.2010.08.004

8. Jenkins PE, Hoste RR, Meyer C, Blissett JM. Eating disorders and quality of life: a review of the literature. Clin Psychol Rev 2011;31(1):113-21.

https://doi.org/10.1016/j.cpr.2010.08.003

9. Powers PS, Perez A, Boyd F, Rosemurgy A. Eating pathology before and after bariatric surgery: a prospective study. Int J Eat Disord 1999;25(3):293-300.

https://doi.org/10.1002/(SICI)1098-108X(199904)25:3<293:: AID-EAT7>3.0.CO;2-G

10. de Zwaan M. Binge eating disorder and obesity. Int J Obes 2001;25(S1):S51-5.

https://doi.org/10.1038/sj.ijo.0801699 
11. Smith BR, Schauer P, Nguyen NT. Surgical approaches to the treatment of obesity: bariatric surgery. Med Clin North Am 2011;95(5):1009-30.

https://doi.org/10.1016/j.mcna.2011.06.010

12. Zeeck A, Stelzer N, Linster HW, Joos A, Hartmann A. Emotion and eating in binge eating disorder and obesity. Eur Eat Disord Rev 2011;19(5):426-37.

https://doi.org/10.1002/erv.1066

13. Tanofsky-Kraff M, Wilfley DE, Young JF, Mufson L, Yanovski SZ, Glasofer DR, Salaita ChG. Preventing excessive weight gain in adolescents: interpersonal psychotherapy for binge eating. Obesity 2007;15(6):1345-55.

https://doi.org/10.1038/oby.2007.162

14. Yanovski SZ. Binge eating disorder and obesity in 2003: could treating an eating disorder have a positive effect on the obesity epidemic? Int J Eat Disord 2003;34(S1):S117-20.

https://doi.org/10.1002/eat.10211

15. Mitchell JE. Medical comorbidity and medical complications associated with binge-eating disorder. Int J Eat Disord 2016;49(3):319-23.

https://doi.org/10.1002/eat.22452

16. Hudson JI, Lalonde JK, Coit CE, Tsuang MT, McElroy SL, Crow SJ, et al. Longitudinal study of the diagnosis of components of the metabolic syndrome in individuals with bingeeating disorder. Am J Clin Nutr 2010;91(6):1568-73.

https://doi.org/10.3945/ajen.2010.29203

17. Molinari E, Baruffi M, Croci M, Marchi S, Petroni ML. Binge eating disorder in obesity: comparison of different therapeutic strategies. Eat Weight Disord 2005;10(3):154-61.

https://doi.org/10.1007/BF03327542

18. van Hanswijck de Jonge P, Van Furth EF, Hubert Lacey J, Waller G. The prevalence of DSM-IV personality pathology among individuals with bulimia nervosa, binge eating disorder and obesity. Psychol Med 2003;33(7):1311-7.

https://doi.org/10.1017/S0033291703007505

19. Peterson CB, Mitchell JE. Psychosocial and pharmacological treatment of eating disorders: a review of research findings. J Clin Psychol 1999;55(6):685-97.

https://doi.org/10.1002/(SICI)1097-4679(199906)55:6<685:: AID-JCLP3>3.0.CO;2-Y

20. Becker S, Rapps N, Zipfel S. Psychotherapie bei Adipositas. Ein systematischer Überlick. Psychother Psych Med 2007;57(11):420-7.

https://doi.org/10.1055/s-2007-986202

21. Faulconbridge LF, Wadden TA, Thomas JG, Jones-Corneille LR, Sarwer DB, Fabricatore AN. Changes in depression and quality of life in obese individuals with binge eating disorder: bariatric surgery versus lifestyle modification. Surg Obes Relat Dis 2013;9(5):790-6.

https://doi.org/10.1016/j.soard.2012.10.010
22. Leahey TM, Crowther JH, Irwin SR. A cognitive-behavioural mindfulness group therapy intervention for the treatment of binge eating in bariatric surgery patients. Cogn Behav Pract 2008;15(4):364-75.

https://doi.org/10.1016/j.cbpra.2008.01.004

23. Marcus MD, Wing RR, Lamparski DM. Binge eating and dietary restraint in obese patients. Addict Behav 1985;10(2):163-8. https://doi.org/10.1016/0306-4603(85)90022-X

\section{BINGE EATING DISORDER: ORIGIN, COMPARISON WITH OTHER EATING DISORDERS AND BASICS OF TREATMENT}

\section{Musneckytė, P. Abraitytė, T. Staniulis}

Keywords: eating, disorders, anorexia, bulimia, binge, obesity. Summary

Binge eating has been only recently acknowledged as a distinct disorder. From 1959 to 2013 binge eating was perceived as one of the features of other eating disorders such as bulimia nervosa. In 2013, binge eating disorder was declared as a separate disorder for the first time in the new revised DSM-5 edition. By 2015, Food and Drug Administration approved lisdexamfetamine dimesilate, a central nervous system stimulant sold under a brand name of "Vyvanse" for treatment of binge eating disorder. This drug primarily was used to treat attention deficit and hyperactivity disorder in adults and children over 6 years old of age before. In recent decade more options for effective treatment and accurate diagnostics were developed. The main attribute of binge eating is that patients are unable to control their impulse to overeat and eating is used as a coping mechanism from stress. Similar to other eating disorders, binge eating manifests in a toxic relationship with food, distorted perception of one's body and mental dysfunction. That causes difficulties in patients daily and social life. However, binge eating also differs from other eating disorders in many ways. Binge eating frequently leads to morbid obesity. Comparing to other eating disorders, obesity is a distinctive symptom of this pathology. Moreover, due to excess body fat these patients suffer from health problems caused by obesity and are often treated by bariatric surgery specialists. Therefore, pharmacotherapy or surgery alone does not cure binge eating disorder. It is important to also treat psychoemotional as well as behaviour issues of the patients. Combined treatment of pharmacotherapy, psychotherapy and surgery is the most effective.

Correspondence to: staniulis.tomas@gmail.com

Gauta 2020-05-25 